\title{
ANALISIS PROBABILITAS KERUNTUHAN PADA LERENG TANAH RESIDUAL DENGAN VARIASI SUDUT KEMIRINGAN LERENG
}

\author{
Thiya Fiantika ${ }^{1}$, Eko Andi Suryo ${ }^{2}$, Harimurti $^{2}$ \\ ${ }^{1}$ Mahasiswa / Program Studi Sarjana Teknik Sipil Fakultas Teknik / Universitas Brawijaya \\ ${ }^{2}$ Dosen / Jurusan Teknik Sipil Fakultas Teknik / Universitas Brawijaya \\ Korespondensi : thiyafiantika@gmail.com
}

\begin{abstract}
Slope is (part of) the side of a hill or mountain. Slope stability became the main concern while working on a construction project, especially on road/highway project. Slope stability determined by soil parameters which include: physical \& mechanical behavior of the soil, ground water level, rock mass structure, etc. Because there is an uncertainty on parameters value in the slope design, causing the slope vulnerable, it needs a concept such as probability analysis to find the stability of the slope. Probability analysis using Monte Carlo method involved a few parameters such as unit weight, cohesion and friction angle. Soil and Slope Geometry data were obtain from prior research. In this analysis there are three trials conducted with various slope angle along with similar material. The result will show a safety factor and failure probability percentage. From this analysis, it can be concluded that the steeper the slope, the lower safety factor number will be shown. The contrary result applied on probability of failure, the steeper the slope, the bigger probability of failure for soil material will occur.
\end{abstract}

Keyword: Monte Carlo, safety factor, probability analysis

\section{PENDAHULUAN}

Lereng adalah bagian yang miring atau sisi yang landai pada sebuah bukit, gunung, perbukitan, ataupun pegunungan Kondisi lereng yang tidak stabil berpotensi untuk memicu bencana longsor. Longsor yaitu suatu kejadian atau peristiwa yang disebabkan oleh pergeseran batuan atau tanah yang menuruni suatu lereng. Jalur Batu - Pujon merupakan jalur yang melewati banyak pegunungan dan lereng. Potensi longsor di wilayah tersebut sangat besar terjadi karena topografi wilayah tersebut adalah terdiri dari pegunungan, sehingga banyak tebing terjal yang rawan longsor. Selain itu, tanah di jalur Batu-Pujon merupakan tanah residual dimana keberadaan tanah residual mempengaruhi kekuatan dan daya dukung tanah [1]. Dengan terjadinya perubahan fisik tanah tersebut maka timbul permasalahan berupa ketidakstabilan lereng yang menyebabkan terjadinya longsor. Dalam perencanaan pembangunan jalan raya, sudut kemiringan lereng merupakan suatu parameter yang penting agar terhindar dari bencana longsor saat jalan raya tersebut sudah digunakan. Namun ketidakpastian yang terkait dengan geometri lereng, sifat fisik dan mekanik batuan mengakibatkan proses pemilihan sudut kemiringan lereng yang sesuai menjadi sulit. Oleh karena itu diperlukan suatu analisis untuk menyelidiki besarnya peluang atau kemungkinan terjadinya keruntuhan lereng dari kemiringan lereng yang dapat dihitung menggunakan analisis probabilitas. Pada metode analisis probabilitas, data yang digunakan adalah semua data properti tanah yang mengakomodasi setiap variasi yang terjadi, contohnya adalah hasil Cone Penetration Test (CPT) [2].

Dalam penelitian ini akan menganalisis lereng di Gunung Banyak Batu, Jawa Timur. Analisis berupa angka keamanan dan probabilitas keruntuhan pada lereng tersebut. Selanjutnya kemiringan pada lereng dirubah dan dianalisis kembali agar dapat dibandingkan hasilnya.

\section{DASAR TEORI}

\subsection{Stabilitas Lereng}

Stabilitas lereng merupakan suatu analisis stabilitas tanah pada permukaan yang miring. 
Dalam menentukan kestabilan lereng atau kemantapan lereng dikenal dengan istilah faktor keamanan (factor of safety) yang merupakan perbandingan antara gaya penahan terhadap gaya penggerak

$\mathrm{FS}=\frac{\text { Gaya Penahan }}{\text { Gaya Penggerak }}=\frac{\tau_{f}}{\tau_{d}}$

dengan :

FS : Faktor keamanan

$\tau_{f} \quad:$ Kuat geser tanah rata-rata $\left(\mathrm{kN} / \mathrm{m}^{2}\right)$

$\tau_{d} \quad$ : Tegangan geser yang terjadi pada sepanjang bidang longsor yang potensial $\left(\mathrm{kN} / \mathrm{m}^{2}\right)$.

\subsection{Tanah Residual}

Tanah residual merupakan tanah yang terbentuk dari hasil pelapukan batuan yang kemudian diendapkan di atas batuan induknya, oleh karena itu biasanya pada tanah residual kuat geser tanah meningkat berdasarkan kedalaman, ini disebabkan oleh bagian tanah yang dekat permukaan telah mengalami pelapukan yang lebih besar dibandingkan dengan tanah di bawahnya. Beberapa faktor yang mempengaruhi kandungan mineral tersebut antara lain iklim, topografi, dan nilai asam basa dari air yang mengalir di lokasi tersebut [3].

Berdasarkan pada hasil uji fisik tanah, maka tanah residual yang merupakan pelapukan batuan breksi mempunyai ketebalan $1-1,6 \mathrm{~m}$ dengan susunan tanah lempung, lanau, pasir kasar dan batuan induk dimana termasuk tanah anorganik dengan plastisitas rendah [4]. Sedangkan berdasarkan penelitian yang dilakukan terhadap tanah residu batuan sedimen, diketahui bahwa ketebalan tanah residu adalah 2,40 - 14,20 m dengan susunan pasir, lanau, dan lebih banyak lempung sehingga plastisitasnya tinggi [5].

\subsection{Metode Analisis}

Metode kesetimbangan batas adalah metode yang menggunakan kesetimbangan gaya. Metode analisis ini pertama-tama mengasumsikan bidang kelongsoran yang dapat terjadi.

\section{a. Metode Morgenstern-Price}

Dalam perhitungan kestabilan lereng, metode ini mempertimbangkan semua gaya yang bekerja pada setiap irisan, yaitu gaya normal dan gaya geser pada irisan. Metode ini cocok digunakan untuk analisis kestabilan lereng menggunakan bantuan software karena keakuratannya dalam menghitung angka keamanan. Analisis dengan metode ini digunakan pada beberapa contoh kasus salah satunya adalah analysis kestabilan lereng di Diamond Hill Citraland [6].

\section{b. Metode Fellenius}

Fellinius mempunyai asumsi bahwa massa tanah di atas bidang longsor dibagi dalam potongan-potongan vertikal. Lebar dari potongan ini dipilih sembarang, tidak harus sama. Untuk keperluan praktis, dasar setiap potongan harus hanya melewati satu jenis tanah dan lebar potongan diambil sedemikian rupa sehingga lengkung busur dapat disederhanakan menjadi garis lurus. Dalam metode ini semua gaya antar irisan diabaikan. Metode ini cocok untuk perhitungan angka keamanan secara manual.

\section{c. Metode Bishop}

Metode ini pada dasarnya sama dengan metode Fellenius, tetapi metode ini memperhitungkan gaya antar irisan yang ada yaitu berupa gaya normal saja. Untuk menghitung angka keamanan, metode ini menggunakan cara coba-coba. Perbandingan dari ketiga metode dapat dilihat pada Tabel 1 dan Tabel 2.

Tabel 1. Perbandingan Kesetimbangan Antar Metode

\begin{tabular}{|c|c|c|c|}
\hline \multirow{2}{*}{ Metode } & \multicolumn{2}{|c|}{ Kesetimbangan Gaya } & \multirow{2}{*}{$\begin{array}{c}\text { Kesetimba } \\
\text { ngan } \\
\text { Momen }\end{array}$} \\
\hline & Vertikal & Horizontal & \\
\hline Fellenius & Tidak & Tidak & Ya \\
\hline Bishop & Ya & Tidak & Ya \\
\hline $\begin{array}{l}\text { Morgenstern- } \\
\text { Price }\end{array}$ & Ya & $\mathrm{Ya}$ & Ya \\
\hline
\end{tabular}

Tabel 2. Gaya Antar Irisan Setiap Metode

\begin{tabular}{ccc}
\hline \multirow{2}{*}{ Metode } & \multicolumn{2}{c}{ Gaya Antar Irisan } \\
\cline { 2 - 3 } & Normal & Geser \\
\hline Fellenius & Tidak & Tidak \\
Bishop & Ya & Tidak \\
Morgenstern- & Ya & Ya \\
Price & &
\end{tabular}

\subsection{Analisis Probabilitas}

Analisis probabilitas adalah suatu nilai yang digunakan untuk mengukur tingkat terjadinya suatu kejadian yang acak. Probabilitas dalam statistik adalah memperkirakan terjadinya peluang yang dihubungkan dengan terjadinya peristiwa tersebut dalam keadaan. Probabilitas secara 
umum merupakan peluang bahwa sesuatu akan terjadi. Probabilitas sangat dibutuhkan, karena kebenaran dari suatu kesimpulan yang dibuat dari analisis data sebetulnya tidak dapat dipastikan benar secara absolut, disebabkan data berasal dari sampel.

\subsection{Simulasi Monte Carlo}

Simulasi Monte Carlo didefinisikan sebagai teknik sampling statistik yang digunakan untuk memperkirakan solusi terhadap masalah-masalah kuantitatif. Metode Monte Carlo mengsimulasikan sistem tersebut berulang-ulang kali, ratusan bahkan hingga ribuan. Hasil yang didapatkan dari simulasi tersebut adalah sebuah distribusi probabilitas dari nilai sebuah sistem secara keseluruhan.

\subsection{Kemiringan Lereng}

Kemiringan lereng merupakan ukuran kemiringan lahan relative terhadap bidang datar yang secara umum dinyatakan dalam persen atau derajat. Sudut kemiringan lereng yaitu sudut yang dibentuk oleh garis horizontal dengan kemiringan lereng timbunan atau galian.

\section{METODE PENELITIAN}

Penelitian ini dilakukan di Gunung Banyak Batu, Jawa Timur.

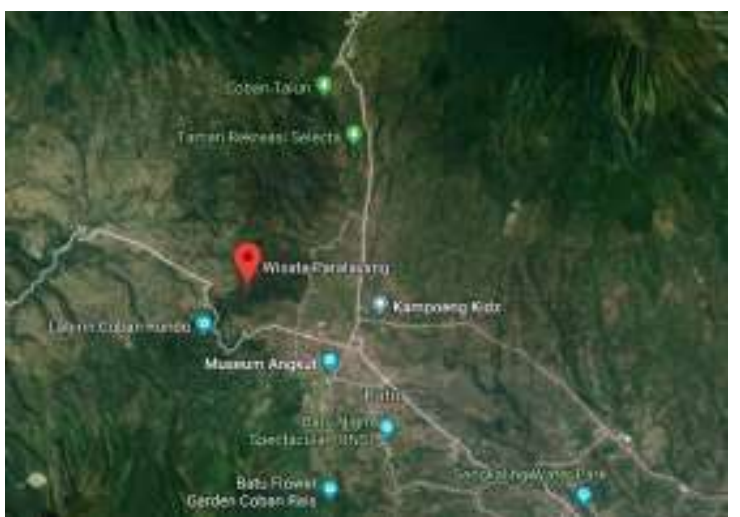

Gambar 2. Lokasi Penelitian

Penelitian ini menggunakan data sekunder berupa penelitian sebelumnya yang dilakukan tepat pada daerah tempat penelitian, yaitu Gunung Banyak Batu, Jawa Timur. Data yang didapatkan berupa data lapangan dan data laboratorium. Data lapangan berupa Sondir dan SPT. Untuk data laboratorium dapat dilihat pada Tabel 3 s.d Tabel 8.
Tabel 3. Hasil Pemeriksaan Kadar Air

\begin{tabular}{cc}
\hline Kedalaman $(\mathbf{m})$ & Kadar Air $(\%)$ \\
\hline $2-2,5$ & 26,54 \\
$3,5-4$ & 38,68 \\
$5-5,5$ & 58,74 \\
$8-8,5$ & 63,02 \\
$9,5-10$ & 21,67 \\
$11-11,5$ & 71,22 \\
$14-14,5$ & 94,53 \\
\hline
\end{tabular}

Tabel 4. Hasil Pemeriksaan Density Test

\begin{tabular}{|c|c|c|c|c|c|c|}
\hline \multirow{3}{*}{$\begin{array}{l}\text { Kedalaman } \\
(\mathrm{m})\end{array}$} & \multicolumn{6}{|c|}{ Parameter } \\
\hline & \multirow{2}{*}{$\frac{\gamma \mathrm{d}}{\mathrm{gr} / \mathrm{cm}^{3}}$} & \multirow{2}{*}{$\begin{array}{l}\text { Isi } \\
\text { Pori }\end{array}$} & \multirow{2}{*}{$\begin{array}{c}\begin{array}{c}\text { Derajat } \\
\text { Kejenuhan }\end{array} \\
(\%)\end{array}$} & \multirow{2}{*}{$\begin{array}{c}\text { Porositas } \\
(\%)\end{array}$} & \multirow{2}{*}{$\frac{\gamma}{\left(\mathrm{gr} / \mathrm{cm}^{3}\right)}$} & \multirow{2}{*}{$\begin{array}{l}\text { Klasifika } \\
\text { si USCS }\end{array}$} \\
\hline & & & & & & \\
\hline $2-2,5$ & 1,5183 & 4,95 & 90,88 & 45,84 & 1,9353 & SM \\
\hline $3,5-4$ & 1,302 & 5,47 & 92,27 & 50,62 & 1,7693 & SM \\
\hline $5-5,5$ & 0,985 & 6,61 & 90,48 & 61,43 & 1,5403 & SM \\
\hline $8-8,5$ & 0,8823 & 7,28 & 80,28 & 67,4 & 1,4233 & SM \\
\hline $9,5-10$ & 1,494 & 5,22 & 61,8 & 48,3 & 1,7927 & SM \\
\hline $11-11,5$ & 0,699 & 7,78 & 69,51 & 72,02 & 1,2003 & SM \\
\hline $14-14,5$ & 0,6273 & 8,16 & 78,63 & 75,55 & 1,2213 & SM \\
\hline
\end{tabular}

Tabel 5. Hasil Pemeriksaan Specific Gravity

\begin{tabular}{cc}
\hline Kedalaman $(\mathbf{m})$ & GS \\
\hline $2-2,5$ & 2,804 \\
$3,5-4$ & 2,637 \\
$5-5,5$ & 2,553 \\
$8-8,5$ & 2,706 \\
$9,5-10$ & 2,89 \\
$11-11,5$ & 2,501 \\
$14-14,5$ & 2,567 \\
\hline
\end{tabular}

Tabel 6. Hasil Pemeriksaan Batas Atterberg

\begin{tabular}{cccc}
\hline Kedalaman & LL & PL & PI \\
\hline $\mathbf{( m )}$ & $\mathbf{( \% )}$ & $\mathbf{( \% )}$ & $\mathbf{( \% )}$ \\
\hline $2-2,5$ & 28,41 & 25,55 & 2,86 \\
$11-11,5$ & 65,52 & 63,21 & 2,3 \\
$14-14,5$ & 72,13 & 68,54 & 3,59 \\
\hline
\end{tabular}

Tabel 7. Hasil Pemeriksaan Direct Shear

\begin{tabular}{ccc}
\hline Kedalaman & Kohesi & $\begin{array}{c}\text { Sudut Geser } \\
\text { Dalam }\end{array}$ \\
\hline $\mathbf{m}$ & $\mathbf{k g} / \mathbf{c m}^{\mathbf{2}}$ & $\mathbf{0}$ \\
\hline $2-2,5$ & 0,155 & 24,986 \\
$3,5-4$ & 0,066 & 21,146 \\
$8-8,5$ & 0,0867 & 37,722 \\
$9,5-10$ & 0,1307 & 38,443 \\
$11-11,5$ & 0,155 & 24,986 \\
$14-14,5$ & 0,0928 & 40,394 \\
\hline
\end{tabular}


Tabel 8. Hasil Pemeriksaan Triaxial

\begin{tabular}{ccc}
\hline Kedalaman & Kohesi & Sudut Geser Dalam \\
\hline $\mathbf{m})$ & $\mathbf{( k g / \mathbf { c m } ^ { 2 } )}$ & $\mathbf{0}$ \\
\hline $5-5,5$ & 0,755 & 11,32 \\
\hline
\end{tabular}

Metode probabilitas yang digunakan yaitu metode Simulasi Monte Carlo dengan bantuan software Geostudio SLOPE/W 2018 dengan variabel parameter masukkan berupa berat jenis $(\gamma)$, kohesi (c), dan sudut geser dalam (Ø). Percobaan Monte Carlo dilakukan sebanyak 2000 kali percobaan.

\section{Gambar 3.}

Diagram alir penelitian diperlihatkan pada

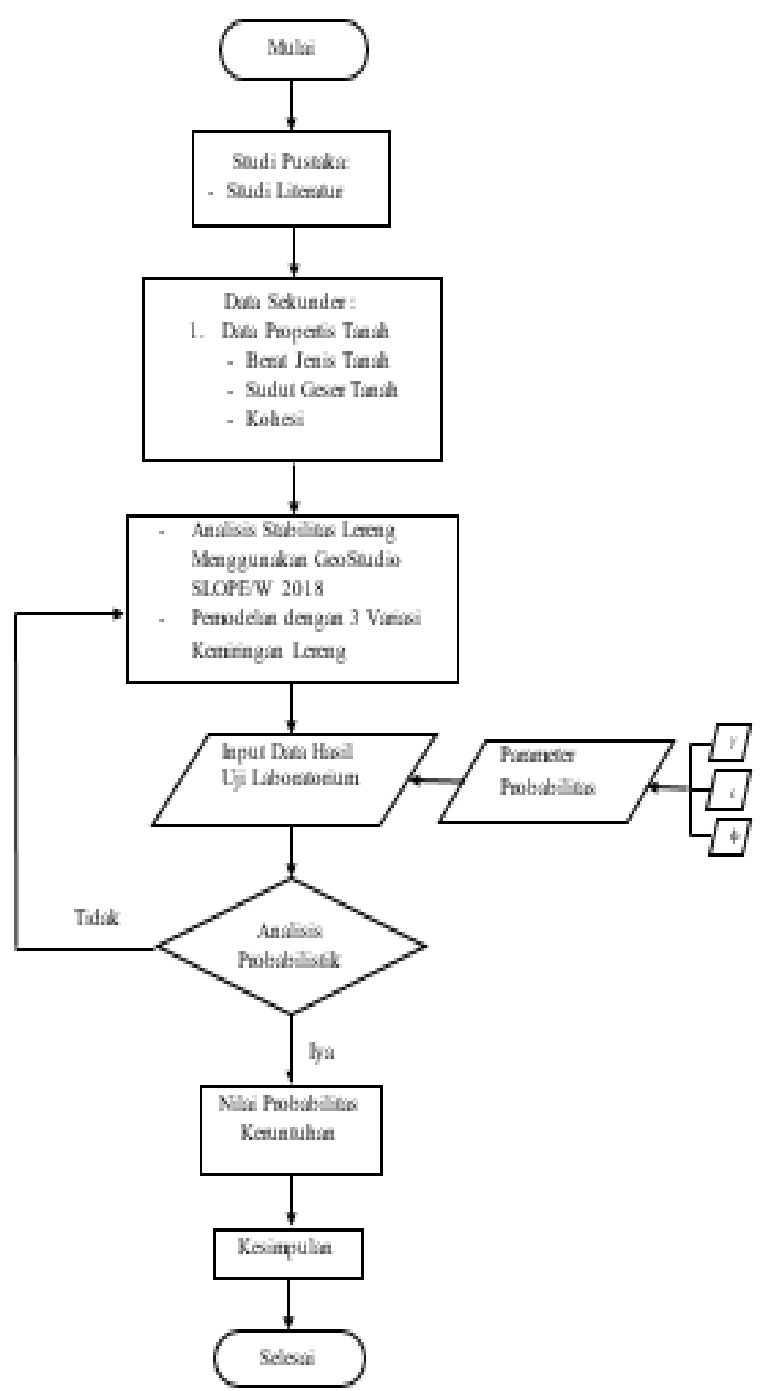

Gambar 3. Diagram alir penelitian

\section{HASIL DAN PEMBAHASAN 4.1 Penentuan Lereng Kritis}

Pemodelan lereng ditentukan berdasarkan hasil dari topografi dan penyatuan hasil geolistrik dari hasil penelitian sebelumnya yang dilakukan di daerah Gunung Banyak Batu, Jawa Timur sehingga didapatkan geometri lereng yang digambarkan pada software seperti Gambar 4.

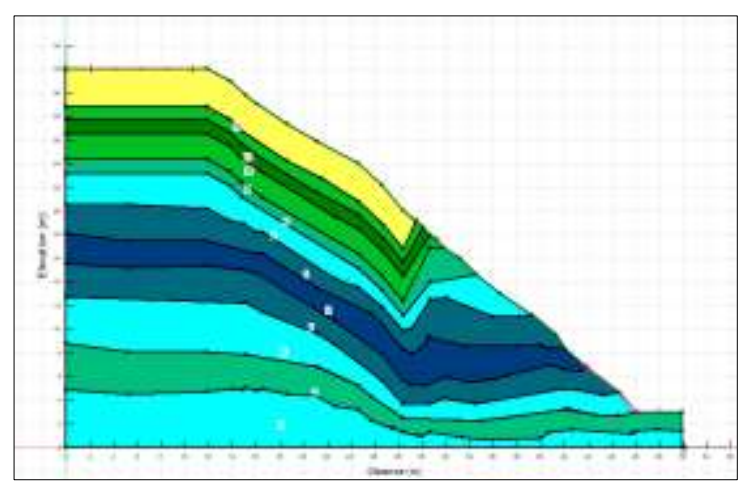

Gambar 4. Geometri lereng pada software

Geometri lereng pada Gambar 4 merupakan keadaan lereng asli dan data parameter tanah dapat dilihat pada Tabel 9.

Tabel 9. Parameter pada lereng

\begin{tabular}{|c|c|c|c|}
\hline \multirow{2}{*}{ Kode Warna } & $\gamma$ & c & Ø \\
\hline & $\mathrm{kN} / \mathrm{m}^{3}$ & $\mathrm{kN} / \mathrm{m}^{2}$ & 0 \\
\hline$\square$ & 14,97 & 14,30 & 31,715 \\
\hline 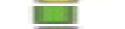 & 19,35 & 15,50 & 24,986 \\
\hline & 19,35 & 15,50 & 24,986 \\
\hline$\square$ & 19,35 & 15,50 & 24,986 \\
\hline 1 & 17,62 & 16,70 & 34,554 \\
\hline 11 & 14,79 & 40,70 & 25,049 \\
\hline & 15,40 & 75,50 & 11,32 \\
\hline ] & 17,69 & 6,60 & 21,146 \\
\hline$\square$ & 15,40 & 75,50 & 11,32 \\
\hline$\square$ & 14,79 & 40,70 & 25,049 \\
\hline$\square$ & 17,62 & 16,70 & 34,554 \\
\hline$\square$ & 14,79 & 40,70 & 25,049 \\
\hline
\end{tabular}

\subsection{Analisis Lereng - 1}

Lereng dianalisis menggunakan software Geostudio SLOPE/W 2018 dengan memasukkan data parameter tanah setiap lapisan sehingga didapatkan angka keamanan pada lereng tersebut. Hasil analisis menunjukkan angka keamanan sebesar 1,080. Untuk menghitung probabilitas keruntuhan pada lereng diperlukan variabel masukkan berupa berat jenis $(\gamma)$, kohesi (c), dan sudut geser dalam (Ø) dengan memasukkan nilai rata-rata serta standar deviasi. Variabel yang digunakan dapat dilihat pada Tabel 10.

Hasil dari analisis dengan memasukkan parameter yang telah ditentukan menghasilkan probabilitas keruntuhan pada lereng yaitu sebesar 10,48 \%. Hasil ini didapatkan dari simulasi Monte Carlo sebanyak 2000 percobaan yang telah diproses oleh software. Hasil analisis dapat dilihat pada Tabel 11. 
Tabel 10. Parameter masukkan

\begin{tabular}{|c|c|c|c|c|c|c|}
\hline \multirow{2}{*}{ Kode Warna } & $\gamma$ & \multirow{2}{*}{$\begin{array}{l}\text { Standar } \\
\text { Deviasi }\end{array}$} & \multirow{2}{*}{$\frac{c}{k N / m^{2}}$} & \multirow{2}{*}{$\begin{array}{l}\text { Standar } \\
\text { Deviasi }\end{array}$} & \multirow{2}{*}{ Ø } & \multirow{2}{*}{$\begin{array}{l}\text { Standar } \\
\text { Deviasi }\end{array}$} \\
\hline & $\mathrm{kN} / \mathrm{m}^{3}$ & & & & & \\
\hline 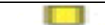 & 14,97 & 1 & 14,30 & 3 & 31,715 & \\
\hline$\square$ & 19,35 & 1 & 15,50 & 3 & 24,986 & 3 \\
\hline$\square$ & 19,35 & 1 & 15,50 & 3 & 24,986 & 3 \\
\hline$\square$ & 19,35 & 1 & 15,50 & 3 & 24,986 & 3 \\
\hline$\square$ & 17,62 & 1 & 16,70 & 3 & 34,554 & 3 \\
\hline$\square$ & 14,79 & 1 & 40,70 & 3 & 25,049 & 3 \\
\hline$\rightarrow$ & 15,40 & 1 & 75,50 & 3 & 11,32 & 3 \\
\hline$\square$ & 17,69 & 1 & 6,60 & 3 & 21,146 & 3 \\
\hline$\square$ & 15,40 & 1 & 75,50 & 3 & 11,32 & 3 \\
\hline$\square$ & 14,79 & 1 & 40,70 & 3 & 25,049 & 3 \\
\hline$\square$ & 17,62 & 1 & 16,70 & 3 & 34,554 & 3 \\
\hline 1 & 14,79 & 1 & 40,70 & 3 & 25,049 & 3 \\
\hline
\end{tabular}

Tabel 11. Hasil Analisis Probabilitas Lereng

\begin{tabular}{cc}
\hline Keterangan & Hasil \\
\hline Rata-rata Faktor Keamanan & 1,082 \\
Indeks Reabilitas & 1,2432 \\
Probabilitas Keruntuhan (\%) & 10,48 \\
Standar Deviasi & 0,0662 \\
Min Faktor Keamanan & 0,816 \\
Maks Faktor Keamanan & 1,323 \\
Monte Carlo Trial & 2000 \\
\hline
\end{tabular}

Dari proses simulasi Monte Carlo yang dilakukan pada software maka didapatkan angka minimum faktor keamanan sampai dengan maksimum faktor keamanan yang dapat ditunjukkan pada Gambar 5 grafik fungsi distribusi probabilitas. Hasil perhitungan probabilitas kumulatif yang didapatkan dari fungsi kepadatan probabilitas kemudian digambarkan menjadi grafik fungsi distribusi probabilitas seperti pada Gambar 6.

\subsection{Analisis Lereng - 2}

Lereng yang diteliti diasumsikan akan dibuat konstruksi jalan, sehingga dilakukan pemotongan lereng selebar $7 \mathrm{~m}$. Setelah dilakuan pengurangan lebar dan tinggi lereng, maka kemiringan lereng berubah seperti pada Gambar 7.

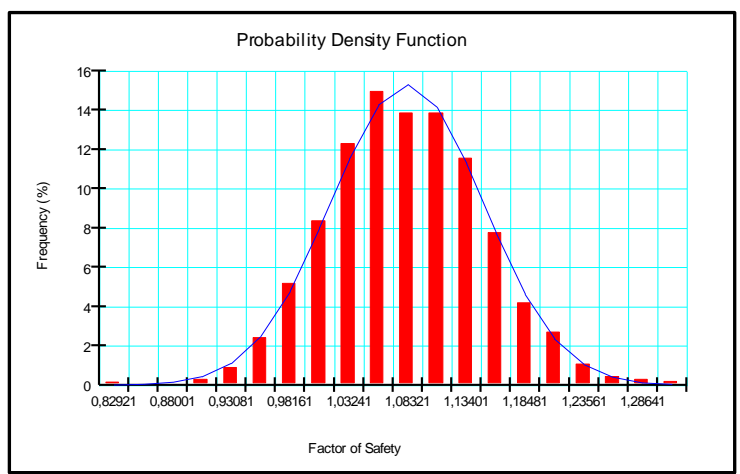

Gambar 5. Fungsi Kepadatan Probabilitas

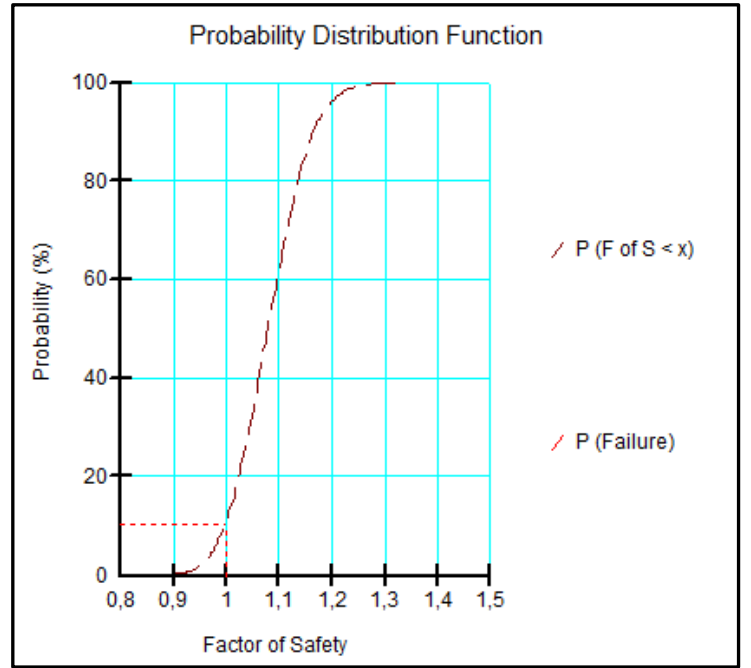

Gambar 6. Fungsi Distribusi Probabilitas

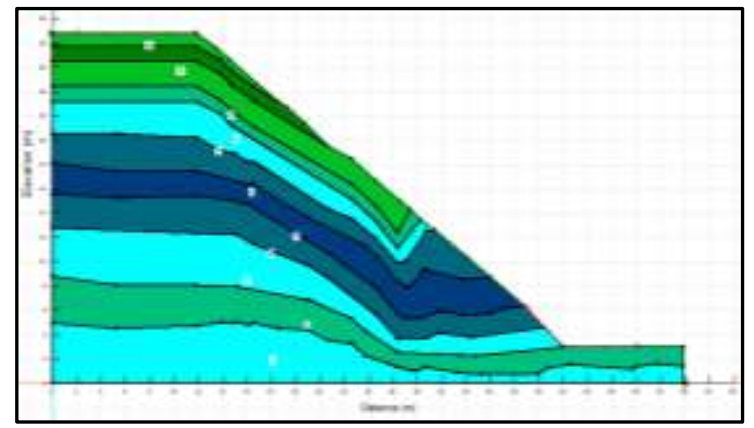

Gambar 7. Geometri Lereng

Hasil analisis menunjukkan angka keamanan sebesar 1,089 dengan probabilitas keruntuhan 10,96\%. Hasil analisis probabilitas dapat dilihat pada Tabel 12.

Tabel 12. Hasil Analisis Probabilitas

\begin{tabular}{cc}
\hline Keterangan & Hasil \\
\hline Rata-rata Faktor Keamanan & 1,089 \\
Indeks Reabilitas & 1,264 \\
Probabilitas Keruntuhan (\%) & 10,96 \\
Standar Deviasi & 0,0708 \\
Min Faktor Keamanan & 0,859 \\
Maks Faktor Keamanan & 1,331 \\
Monte Carlo Trial & 2000 \\
\hline
\end{tabular}

Grafik fungsi kepadatan probabilitas dan grafik fungsi distribusi perobabilitas dapat dilhat pada Gambar 8 dan Gambar 9. 


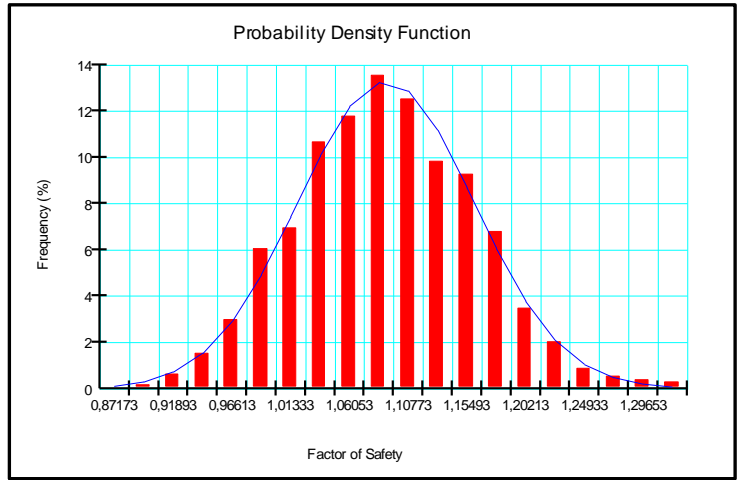

Gambar 8. Fungsi Kepadatan Probabilitas

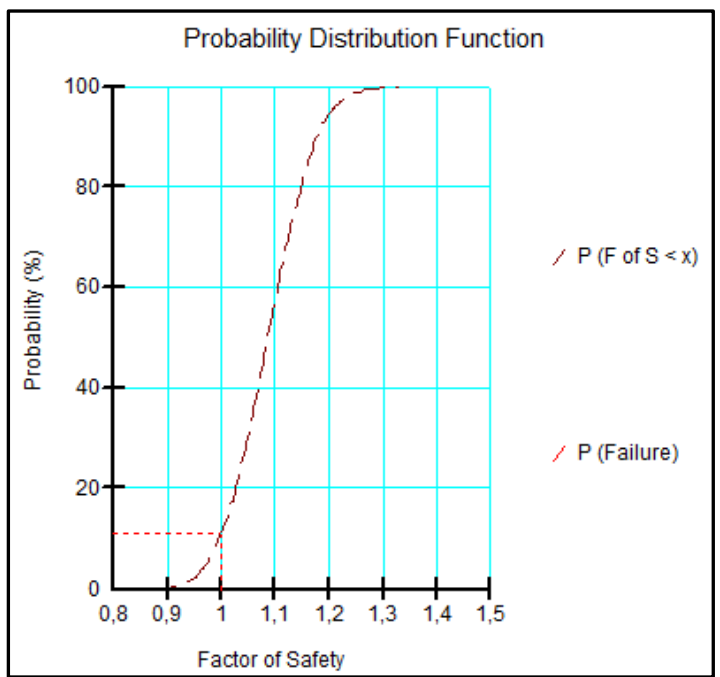

Gambar 9. Fungsi Distribusi Probabilitas

\subsection{Analisis Lereng - 3}

Geometri lereng ke 3 diasumsikan pemotongan lebar lereng sepanjang $7 \mathrm{~m}$, tetapi untuk tinggi lereng tidak dikurangi. Sehingga kemiringan lereng lebih terjal dibandingkan lereng pertama dan kedua. Geometri lereng ke tiga dapat dilihat pada Gambar 10.

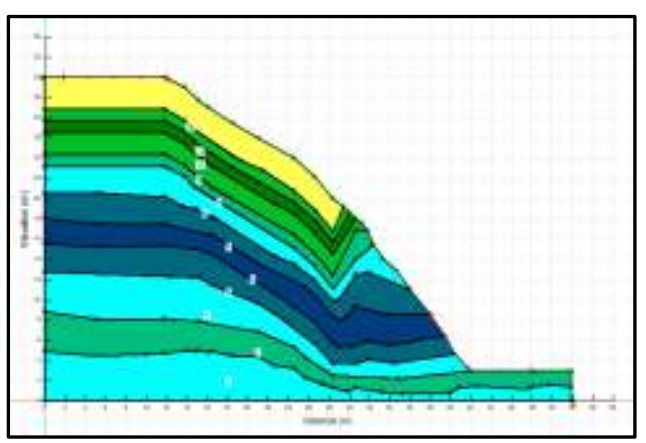

Gambar 10. Geometri Lereng

Hasil analisis menunjukkan angka keamanan sebesar 0,938 dengan probabilitas keruntuhan 82,15 \%. Probabilitas keruntuhan yang besar menyatakan bahwa kemungkinan terjadinya longsor semakin besar. Hal ini terjadi karena lereng yang terlalu terjal. Hasil analisis probabilitas dapat dilihat pada Tabel 13.

Tabel 13. Hasil Analisis Probabilitas

\begin{tabular}{cc}
\hline Keterangan & Hasil \\
\hline Rata-rata Faktor Keamanan & 0,938 \\
Indeks Reabilitas & $-0,919$ \\
Probabilitas Keruntuhan (\%) & 82,15 \\
Standar Deviasi & 0,0667 \\
Min Faktor Keamanan & 0,637 \\
Maks Faktor Keamanan & 1,191 \\
Monte Carlo Trial & 2000 \\
\hline
\end{tabular}

Grafik fungsi kepadatan probabilitas dan grafik fungsi distribusi perobabilitas dapat dilhat pada Gambar 11 dan Gambar 12.

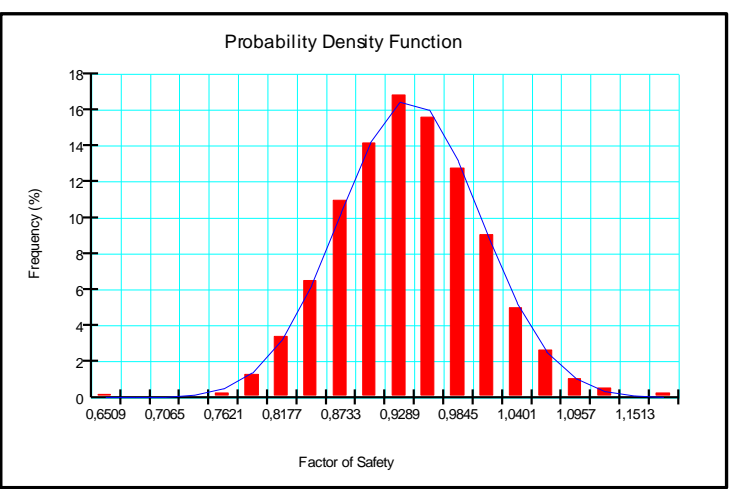

Gambar 11. Fungsi Kepadatan Probabilitas

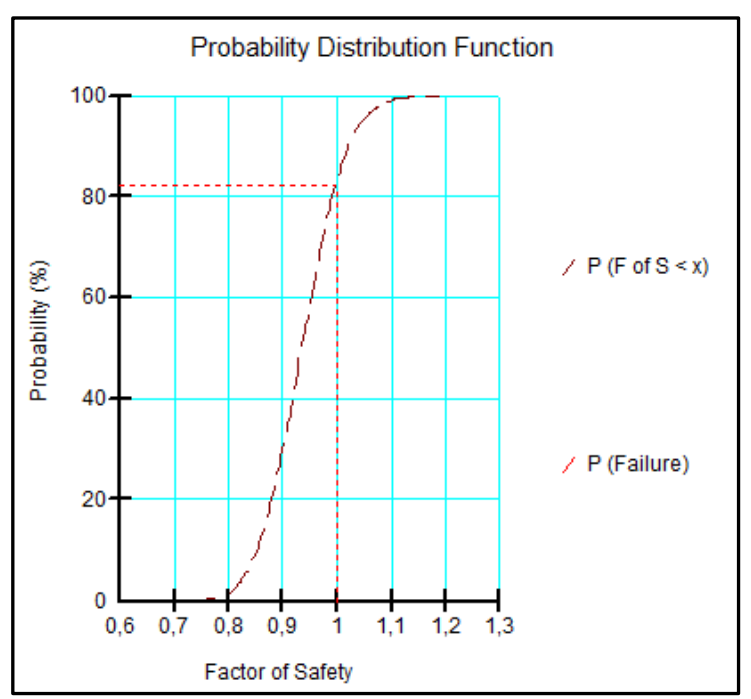

Gambar 12. Fungsi Distribusi Probabilitas

\subsection{Perbandingan Hasil Analisis}

Dari hasil analsis yang didapatkan dari ketiga lereng di atas maka didapatkan 
perbandingan yang akan ditampilkan pada Tabel 14.

Tabel 14. Perbandingan Hasil Analisis

\begin{tabular}{cccccc}
\hline Lereng & $\begin{array}{c}\text { Tinggi } \\
(\mathrm{m})\end{array}$ & $\begin{array}{c}\text { Lebar } \\
(\mathrm{m})\end{array}$ & $\begin{array}{c}\text { Sudut } \\
\left({ }^{\circ}\right)\end{array}$ & $\begin{array}{c}\text { Faktor } \\
\text { Keamanan }\end{array}$ & $\begin{array}{c}\text { Probabilitas } \\
\text { Keruntuhan } \\
(\%)\end{array}$ \\
\hline 1 & 32 & 52 & 33 & 1,082 & 10,48 \\
2 & 28 & 42 & 32 & 1,089 & 10,69 \\
3 & 32 & 42 & 37 & 0,938 & 82,15 \\
\hline
\end{tabular}

\section{PENUTUP}

\subsection{Kesimpulan}

1. Hasil analisis stabilitas lereng pada daerah Gunung Banyak menunjukkan angka keamanan yaitu sebesar 1,082. Hal ini membuktikan bahwa lereng dalam keadaan stabil tetapi dapat terjadi ketidakstabilan karena angka keamanan yang sangat mendekati angka 1.

2. Probabilitas keruntuhan lereng pada daerah Gunung Banyak menggunakan analisis probabilitas pada software GeoStudio 2018 SLOPE/W menunjukkan angka sebesar $10,48 \%$. Hal ini mengartikan bahwa kemungkinan lereng tersebut terjadi keruntuhan sebesar 10,48\%.

3. Hasil analisis lereng ke 2 dengan perubahan lebar dan ketinggian lereng menunjukkan angka keamana 1,089 dengan probabilitas keruntuhan sebesar 10,69\%. Sedangkan hasil dari analisis lereng ke 3 dengan perubahan lebar lereng tanpa perubahan ketinggian lereng menunjukkan angka keamana 0,938 dengan probabilitas keruntuhan sebesar 82,15\%.

4. Probabilitas keruntuhan lereng saat terjadi perubahan kemiringan lereng berbedabeda. Pemotongan pada lereng dapat merubah kemiringan dari sebuah lereng. Semakin terjal suatu lereng maka probabilitas keruntuhannya semakin besar untuk kasus lereng yang diteliti pada penelitian ini.

\subsection{Saran}

1. Perlu dilakukan navigasi GPS agar lokasi lereng yang diteliti dapat lebih akurat dalam penentuan lereng kritisnya.

2. Untuk menentukan lapisan lereng sebaiknya dilakukan pengujian berupa SPT (Standard Penetration Test) di beberapa titik. Pada penelitian ini hanya dilakukan pada satu titik, sehingga sulit dalam menentukan lapisan lereng.

3. Pada penelitian ini tidak dimasukkan data curah hujan dan data gempa, oleh karena itu kedepannya apabila ada penelitian sejenis dapat memasukkan data-data tersebut agar hasil dapat lebih akurat.

4. Perlu dilakukan perhitungan dan penanganan kelongsoran lebih lanjut guna meningkatkan faktor keamanan lereng sehingga lereng menjadi lebih stabil.

\section{DAFTAR PUSTAKA}

[1] Wibowo, Y. Sunarya, Perilaku Sifat Fisik dan Keteknikan Tanah Residual Batuan Volkanik Kuarter di Daerah Cikijing, Majalengka, Jawa Barat, Riset Geologi dan Pertambangan, Vol. 2, 2011.

[2] Listyawan, A. B.; Senja R. H.; Bayu C., Analisis Probabilitas Stabilitas Lereng Tanah Lempung Jenuh. Dinamika Teknik Sipil Vol.12, No.2, 2012.

[3] Wesley, L.D. Geotechnical Engineering in Residual Soils. John Wiley and Sons, Inc, United States of America.2010.

[4] Wibowo, Y. S.; Perilaku Sifat Fisik dan Keteknikan Tanah Residual Batuan Volkanik Kuarter di Daerah Cikijing, Majalengka, Jawa Barat. Riset Geologi dan Pertambangan, Vol.21, No.2, 2011.

[5] Sudarsono, U.; Hasibuan G.; Karakteristik Geologi Teknik Tanah Residu Batuan Sedimen Kuarter Bawah Daerah Kertajati, Majalengka, Jawa Barat, Jurnal Geologi Indonesi, Vol.6, No.3, 2011.

[6] Takwin, G. A.; Turangan A. E.; Steeve G. R. Analisis Kestabilan Lereng Metode Morgenstern-Price (Studi Kasus : Diamond Hill Citraland), Tekno Vol. 15, No.67, 2017. 